ERIN MOURÉ is a poet, training developer, and service designer who lives, works, and writes in Montréal. Her books of poetry are Empire, York Street (Anansi, 1979). The Whisky Vigil (Harbour, 1981), Wanted Alive (Anansi, 1983), and most recently, Domestic Fuel (Anansi, 1985) which won the Pat Lowther Memorial Award. A new book of poems, Furious, is near completion.

\title{
To Speak of These Things: A Letter
}

17 April 1986

Montreal

\section{Dear Erin:}

Thinking back maybe ten or eight years ago under the flat leaf shadow of Vancouver streets. Our unease, and some things we said then, stick in my mind. That the real is only the sum of perceptions the most people agree with (like circles whose boundaries cross), and the poetry came from being slightly off-centre. Fed by the not-shared. As if the poet, being off-centre, is better located to respond to the visible. Their duty of witness: as if it is only a response to the visible. We wore the coats of individuals lost in the world, distinctive, carrying our past and memory like talismans of a collective doubt, as if it was past events, that made us.

Yet after a few years of pushing at the English language to have it reflect the visible, reflect events in their timely character, we found gaps. They had to do with individual reason and realization, we thought. With "the inexpressible". With translation from the inexpressible. With the surface commerce of words. With our own inadequacy. The stutter inside us, we thought, was some thing we couldn't speak of in English: there were words for it instead in our lost maternal tongue: in Polish, in French, in the speech of our mothers. We remembered our grandmothers' speaking, the surge and nuance of their voices, we knew something different was being expressed, and remembering this, the English language seemed a narrow tool. But still a tool, outside the individual. For which we weren't responsible.

We didn't connect our feeling about language and off-centredness to our being women. Instead we clung to the connection of "the poet" 
with Rilke's "surplus of existence welling up in the heart". "Are we here perhaps just to say:/ house, bridge, well, gate, jug, fruit tree, window - at most, column, tower... but to say, understand this, to say it/ as the Things themselves never fervently thought to be." Those words that moved us deeply..." Here is the time for the unutterable, here, its country./Speak and acknowledge it. More than ever/the things that we can live by are falling away / supplanted by an action without symbol."

Always there was an "I" that was opposed to the "saying". Our belief in the pure word, as Rilke spoke it:

The wanderer does not bring a handful of earth, the unutterable, from the mountain slope to the valley but a pure word he has learned, the blue and yellow gentian.

For us there had to be a solution for women's speech in individual speaking, some kind of expression in the individual. As if the individual and the utterance were separate, and the first could approach the second. The pure word. In the beginning was the Word. And we, unwittingly, reproduced our stories inside that symbolic order.

Erin, this is how you fed yourself. With this dream of the individual. Pushing at the edge of the dream, the rugged heart, inexpressible but for those few words. If we think too much, or talk about the process, or question it, we lose touch with that source of poetry. As if it was so fragile the thinking could ruin it. "At night you remembered freedom and flew in a dream; the dawns ruined it."

What I want to say now, Erin of 10 years ago, woman of uncertainty, woman of belief in the integrity of the poem and voice in their poem - and voice-ness, oh... What I want to say is that when I look back to you, I see that our dream of the individual is accompanied by a mystifying of "the poem". The source. If you talk about the poem it will go away, we thought, and so we never talked about the poem. If you question the words the poem will fall apart inside, and so we never talked about the poem. The theory is parasitic and comes from outside inspiration and real experience, and so we never talked about the poem. We talked about our individual experience. Trying to connect our oppression. Which as women was economic, numeric, and didn't have to do with the source of the poems or our relationship with language itself.

But trying to connect our oppression through the expression of the purely individual still maintains its hierarchy! The individual: precious, leads to Romanticism of the poem, and cynicism, finally. Cynicism, because romanticism fails in contact with the world. The nagging thought, too, that it is in the interest of the capitalist state to maintain the dream of the individual because people connecting their 
sensations, removing them from the realm of the personal, and analyzing their oppression, threatens the state. By clinging to this notion of the individual, and the idea that only the personal named personally is political, we maintain the notion of individual "power". Who can assail someone's else's past? You can only say you didn't see it that way, at that time, in those days. But you, Erin, can't play this trick on me because you are me, becoming who I am, and I am the one who can question your passing.

At the Women and Words conference in 1983 my own thinking about bodily tensity and here-ness and its reliance on memory and desire, connected with the words themselves. And with my own use of them, with whose voice I was writing, a woman, unquestioning the assumptions the language had fed me like a drug (the truth serum that does not uncover truth but limits the way we see things, until we see only truthfulness).

You see, I've been thinking of memory \& desire, which keep us in the present tense, the tension of that... because they are representations of both the past and the future, inside us, not in the world. Somehow I began to realize that it is language and the words themselves that tie us together in memory and desire, because those two things are mediated in our bodies through language itself, and they constitute a social order, in this case patriarchy, in the body. The individual is created by the utterance. Through the utterance we organize our perceptions of the world.

And I became drawn to working with women, whose perceptions shared between each other made gaps in the meanings that had been spoken of us, through us, since childhood. The gaps craved us, and we them. That feeling of being off-centre, situated apart from the real, we had ten years ago, this is what it is!

I fell through those gaps in meaning and expression and drank the holes in like alcohol. The stories that haunted me since my childhood, the images I carried as palimpsests, rubbed smooth and re-written, I began to feel the smooth surface and ache of, through what-had-beenrubbed-away. And curiously, I looked at my memories, OUR memories, Erin, and found that most of the hidden stories I couldn't tell, that moved me, that had no articulation in the utterance that had formed me as an individual... had to do with women. I started to hear something in the language I had never heard before, the marks of the male; the marks of maleness on the words themselves, the words marked as coins are marked. As metal, pressed, becomes currency. Is attributed a value. Becomes a medium of exchange.

And I tell you we women must, if we are to recognize these marks, and no longer be "exchanged" within their medium, talk about the language of the poem, think and talk about our thinking. This fear we have: of theory, or the academic, those minus-value words we attribute 
to what-engagement (as if experience itself could be spoken without reflection on the language, through which our experience is mediated, to us, \& others!) This fear we have is the self-perpetuation of the hierarchy of patriarchy. And self-perpetuation implies choice, even though it may have been unconscious choice. Just knowing what we know now, can we go back and refuse the choice? Or make it now, choose to recognize and talk of our marking, and break it apart, even using the words we that have marked us, unwitting as we were then.

If we talk the source of the poem won't go away. It will spring loose out of us, our deep well-shaft of the unspeakable. What will go away will be the marking, and we will make a marking of our own. In speech. Not "equal" but different. Our experience. Our womanliness.

To place ourselves at risk, at risk of losing everything, even the meaning of the poem and voice: even so, we women must think and speak these things to each other. It is not really a risk at all, though in our marked language we have no other word for it. The word "risk" only protects the hierarchy in us from its own loss, because it is made of "loss", the loss of women. It is not a risk but an opening. The risk is there only because of our history of refusal. Can you go back now, Erin, and say you have not heard this?

I'm waiting for you to get here, to speak of these things, between us, and among women.

Erin 